\title{
A economia verde como referência para análise das unidades de conservação de uso sustentável no estado do Pará, Brasil
}

\section{The green economy as reference for analysis of sustainable protected areas in Pará State, Brazil}

\author{
Natália Aragão Figueredo \\ nataliaragao@gmail.com \\ Pós-doutoranda de Solos e Nutrição de Plantas pela Universidade Federal de Viçosa \\ (UFV)
}

\section{Thais Helena Teixeira}

thaishel.efa@hotmail.com

Doutoranda em Extensão Rural pela Universidade Federal de Viçosa (UFV)

José Ambrósio Ferreira Neto

ambrosioufv@gmail.com

Professor Departamento de Economia Rural na Universidade Federal de Viçosa (UFV)

Marcelo José Braga

mjbraga@ufv.br

Professor Departamento de Economia Rural na Universidade Federal de Viçosa (UFV)

Recebido em : 05/082017

Aprovado em: 28/08/2017
Revista do Programa de Pós-Graduação em Extensão Rural (UFV) 


\title{
RESUMO
}

As Unidades de Conservação de Uso Sustentável brasileiras buscam a inclusão dos povos tradicionais nas propostas de preservação e manejo ambiental. Este trabalho tem como objetivo contribuir com a discussão sob o prisma da Economia Verde, apresentando o cenário produtivo desenvolvido pelas famílias residentes em Reservas Extrativistas e Floretas Nacionais. Para tanto, se utiliza de informações coletadas por meiode questionários aplicados às famílias moradoras em 25 Unidades de Conservação de Uso Sustentável, entre 2013 e 2014, no estado do Pará. Os principais resultados apontam para existência de uma congruência entre o que é preconizado pela Economia Verde e as realidades das Resex e Flonas estudadas, no que se refere à utilização dos recursos naturais como fator de geração de renda monetária e de segurança alimentar destas famílias, garantindo a perenidade dos recursos ambientais e a manutenção das unidades familiares.

Palavras -chave: Sustentabilidade; Economia; Amazônia.

\begin{abstract}
The Brazilian Sustainable Use Conservation Units seek the inclusion of traditional peoples in the proposals for conservation and environmental management. This work aims to contribute to the discussion about this reality, in the light of the Green Economy, Presenting productive scenario developed by resident households Extractive Reserves and National Forests. Therefore, it uses information collected by questionnaires to families living 25 of Sustainable Use Protected Areas between 2013 and 2014 in the state of Pará. The main results point to the existence of a congruence between what is advocated by the Green Economy and the realities the Resex and Flonas studied in relation to the use of natural resources as monetary income generation factor and food security of these families, ensuring the sustainability of environmental resources and the maintenance of family units.
\end{abstract}

Keywords: Conservation Units; Green Economy; Amazon. 


\section{Introdução}

Nas últimas décadas o mundo passou por importantes processos de reorganização política, social e econômica e, principalmente, na percepção da relação entre sociedade e natureza. A questão ambiental está no centro das atuais preocupações e vêm pressionando mudanças e formando novos paradigmas correlacionados à ideia de desenvolvimento e sustentabilidade.

Nessa perceptiva, uma nova alternativa de desenvolvimento sustentável vem sendo proposta, a denominada Economia Verde, que privilegia a adoção de novas práticas econômicas voltadas para um melhor uso dos recursos naturais. De acordo com a Unep (2010), a Economia Verde é considerada uma forma de "melhoria do bem-estar humano e equidade social, ao mesmo tempo em que reduz significativamente os riscos ambientais e a escassez ecológica". Por sua vez, Victor (2010) define o crescimento "verde", como uma ideia de desenvolvimento econômico associado à redução do impacto ambiental através de tecnologias limpas e baratas que não esgotem os recursos naturais renováveis. Young (2011) contribui nessa análise ao defender que esta nova perspectiva econômica aprimora o conceito de desenvolvimento sustentável por meio da ecologização da economia, onde o elemento basilar é a promoção dos direitos humanos e sociais.

A discussão a respeito da Economia Verde, como um elemento promissor ao desenvolvimento sustentável, foi preconizada pelo Programa das Nações Unidas para o Meio Ambiente (Pnuma) e amplamente abordada na Conferência das Nações Unidas sobre Desenvolvimento Sustentável- Conferência Rio+20, em 2012 - como alternativa emergente aos modelos econômicos atuais, devido à inserção de preceitos como erradicação da pobreza, redução das iniquidades e o uso eficiente dos recursos naturais. Seguindo essas abordagens, vêm sendo desenvolvidos estudos para valorizar os usos múltiplos do meio ambiente, principalmente a economia das florestas. Diante da abundância de áreas florestais no território brasileiro, estas possuem uma importância fundamental para a preservação e garantia da qualidade ambiental, como também são essenciais para as populações tradicionais ali inseridas, que dependem diretamente dos recursos naturais existentes nessas áreas.

Atualmente, o Brasil possui em seu território cerca de 131 Unidades de Conservação de Usos Sustentável (UCUS)federais, apenas nas categorias Reserva Extrativista (Resex), Reserva de Desenvolvimento Sustentável (RDS) e Floresta Nacional (Flona) (CNUC, 2017). Essas UCUS evidenciam grande potencial de desenvolvimento 
do modelo proposto pela Economia Verde, pelo atendimento à preservação e conservação ambiental, como também da utilização racional da terra, por meio das práticas do extrativismo vegetal e da agricultura tradicional. Alguns exemplos são o da biodiversidade para fins medicinais, cosméticos e outros produtos derivativos, turismo ecológico, difusão da gestão ambiental e, principalmente, pela garantia de acesso e uso do território e da segurança alimentar das famílias extrativistas (OLIVEIRA, 2012; MOORE, 2011).

A criação desses espaços protegidos estabelece uma dinâmica de uso e ocupação, sendo uma estratégia governamental de controle do território. Os critérios de uso são atribuídos às UCUS em função da valorização dos recursos naturais e também pela necessidade de proteção dos ecossistemas. Assim, as Unidades de Conservação de Uso Sustentável podem ser consideradas uma contribuição ao desenvolvimento sustentável pela conservação da biodiversidade, fixação de carbono e preservação da diversidade cultural das populações tradicionais (CAVALCANTI, 1994).

De forma geral, os pressupostos intrínsecos da Economia Verde são a substituição entre os recursos, a melhoria na eficiência tecnológica e a valoração do capital natural, estratégias mais sustentáveis de governança tendo em vista o incremento qualitativo da chamada "eco eficiência" (JACOBI, 2012). A ideia central é que o conjunto de processos produtivos da sociedade contribua para a sustentabilidade socioambiental, por meio de uma maior eficiência do uso dos recursos naturais também para fins de geração de renda, através do capital natural.

Assim, o presente estudo tem como objetivo analisar o perfil produtivo das Unidades de Conservação de Uso Sustentável no estado do Pará, considerando os sistemas produtivos como elementos preconizados pela Economia Verde na discussão sobre áreas protegidas na Amazônia brasileira. Na medida em que pretende evidenciar como os recursos naturais são apropriados pela racionalidade produtiva, em contextos marcados pela valorização da sustentabilidade ambiental e formas de sobrevivência das famílias residentes nessas áreas.

\section{Metodologia}

\section{Caracterização da Área de estudo}

O estudo engloba as 25 Unidades de Conservação de Uso Sustentável de esfera federal, existente no estado do Pará, região Norte do Brasil, abrangendo as categorias 
Flona, Resex e RDS. Essas Unidades de Conservação estão distribuídas em sete regiões de integração (RI) conforme ordenamento territorial proposto pelo governo do Pará, são elas: Baixo Amazonas; Região Guamá; Tapajós; Tocantins; Marajó; Rio Caeté e Xingu. Essas UCUS estão ainda divididas em dois ecossistemas, o Amazônico e o Marinho Costeiro,que constituem realidades ambientais e socioeconômicas distintas. As UCUS que estão inseridos no bioma Marinho são as Resex’s São João da Ponta, Mãe Grande de Curuçá, Maracanã, Caeté Taperacú, Araí Peroba, Chocoaré Mato Grosso, Gurupi Piriá, Tracuateua e Soure, as demais estão no bioma Amazônico.

Dentre as regiões de integração (RI) em que se localizam as Unidades de Conservação abordadas neste estudo, a RI do Marajó, localizada no norte do estado, é composto por 12 municípios, com uma população de 487.161 habitantes distribuídos em uma área de 104.139,30 km². Esse território, em função do ecossistema marinho (limite com oceano Atlântico), rio Amazonas e baía do Marajó, constitui uma área de proteção e conservação (IDESP, 2014). Atualmente, existem oito UCUS que correspondem a $37,58 \%$ da área total da região, com 2.219.361,14 hectares, sendo elas: Resex Arioca Pruanã, Resex Gurupá Melgaço, RDS Itatupã Baquiá, Resex Terra Grande Pracuúba, Resex Mapuá, Resex Verde para Sempre, Resex Marinha de Soure e Flona Caxiuanã.

As Reservas Extrativistas Rio Iriri, Rio Xingu e Riozinho do Anfrísio estão localizadas na RI do Xingu que compreende dez municípios do sudoeste do Pará, totalizando 331.770 habitantes, representando 20,25\% do território paraense. Já a Resex Ipaú Anilzinho com 55.835,01 ha e 353 famílias localiza-se no município de Baião, inserido na RI Tocantins, que abrange uma área de 34,6 mil km² (2,8\% do território estadual)(IBGE, 2016).

A RI do Rio Caeté abrange quinze municípios, com uma população de 469.484 habitantes distribuída em 1,3\% do território estadual (IBGE, 2016) e corresponde a área de influência das Resex's Marinhas de Tracuateua, Araí Peroba, Gurupi Piriá e Caeté Taperaçu, as quais possuem como áreas de proteção e conservação 154.692 ha, onde estão inseridas 4.076 famílias. Já a RI Guamá abrange as Resex’s Maracanã, Chocoaré Mato Grosso, Mãe Grande de Curuçá e São João da Ponta, em uma área de abrangência de $73.051,12$ ha com uma população de 18.423 pessoas, totalizando uma área de 12.130,87 $\mathrm{km}^{2}$.

As Unidades de Conservação Resex Renascer, Tapajós Arapiuns e a Flona SaracáTaquera com um total de 3.957 famílias, distribuídas em 1.330.344 ha estão inseridas na 
RI Baixo Amazonas. A RI Tapajós, que se localiza no sudoeste do estado, sendo a menos povoada com 209.531 habitantes e ocupando uma área de $189.592 \mathrm{~km}^{2}$ (IBGE, 2016). As Flona Crepori e a Flona Tapajós com uma área total de 12.710 .17 ha e 869 pessoas residentes e um conjunto de terras indígenas correspondem a 65,66\% da área dessa região.

\section{Procedimentos metodológicos}

Os procedimentos metodológicos utilizados nesta pesquisa foram a investigação bibliográfica sobre as Unidades de Conservação de Uso Sustentável e análises estatísticas de dados secundários. Na investigação bibliográfica, foram utilizados dados provenientes de artigos científicos e sites de órgãos públicos como Ministério do Meio Ambiente MMA, Instituto Brasileiro de Geografia e Estatística - IBGE, Governo do estado do Pará, os quais tiveram a finalidade de acrescentar informações relevantes aos dados analisados, e, também, fornecer informações sobre os municípios de inserção das áreas estudadas.

Em relação aos dados secundários, utilizou-se, como principal fonte, o banco de dados proveniente do projeto de cooperação técnica entre a Universidade Federal de Viçosa e o Instituto Chico Mendes de Conservação da Biodiversidade denominado "Apoio ao processo de Identificação das famílias beneficiárias e Diagnóstico sócioprodutivo em Unidades de Conservação Federais”. Esse projeto teve como objetivo o diagnóstico socioeconômico e levantamento das famílias inseridas nas Unidades de Conservação federais de Uso Sustentável, nas categorias Flona, Resex e RDS, entre 2013 e 2014.

A coleta de dados foi feita com aplicação de questionários baseados nos seguintes agrupamentos de temas: dados socioeconômicos do grupo familiar; área de moradia e uso; residências e benfeitorias; educação e saúde; acesso a serviços (água, saneamento e energia elétrica); produção e comercialização vegetal, pesqueira, animal, pecuária e madeireira; uso da terra e equipamentos; ocupação e origem da renda familiar; organização social e aspectos ambientais.

$\mathrm{O}$ processo de delineamento amostral realizado partiu do pressuposto que as Unidades de Conservação de Uso Sustentável são relativamente homogêneas, podendo ser tratadas como extratos ou subpopulações. Assim, utilizou-se o nível de confiança de 95\%, com erro de amostragem $(\mathrm{E}=0.05)$, correspondendo a uma porcentagem de erro aceitável estatisticamente no processo de estimação da verdadeira proporção. No Quadro 1 são apresentados o quantitativo de questionários aplicados como também a amostragem realizada. 
Quadro 01. Localização das Unidades de Conservação e amostragem da pesquisa, Pará, 2016

\begin{tabular}{|c|c|c|c|c|c|}
\hline $\begin{array}{ll}\text { Unidade } & \mathrm{de} \\
\text { Conservação }\end{array}$ & $\begin{array}{l}\text { Região de } \\
\text { integraçã } \\
\text { o }\end{array}$ & Município & $\begin{array}{l}\text { Questionário } \\
\text { s aplicados }\end{array}$ & $\begin{array}{l}\text { Amostrage } \\
\mathrm{m}\end{array}$ & $\begin{array}{l}\text { Pessoas } \\
\text { cadastradas }\end{array}$ \\
\hline $\begin{array}{l}\text { Flona Saracá- } \\
\text { Taquera }\end{array}$ & \begin{tabular}{|l} 
Baixo \\
Amazona \\
s
\end{tabular} & Faro & 469 & 461 & 1959 \\
\hline $\begin{array}{l}\text { Resex } \quad \text { Tapajós- } \\
\text { Arapiuns }\end{array}$ & \begin{tabular}{|l|} 
Baixo \\
Amazona \\
s
\end{tabular} & Aveiro & 3082 & 201 & 12.036 \\
\hline Resex Renascer & \begin{tabular}{|l} 
Baixo \\
Amazona \\
$\mathrm{s}$
\end{tabular} & Prainha & 406 & 406 & 1757 \\
\hline $\begin{array}{l}\text { Resex São João da } \\
\text { Ponta }\end{array}$ & Guamá & Curuçá & 117 & 117 & 415 \\
\hline $\begin{array}{l}\text { Resex Mãe Grande } \\
\text { de Curuçá }\end{array}$ & Guamá & Curuçá & 2714 & 135 & 9610 \\
\hline Resex Maracanã & Guamá & $\begin{array}{l}\text { Magalhãe } \\
\text { s Barata }\end{array}$ & 1487 & 159 & 5992 \\
\hline $\begin{array}{l}\text { Resex Chocoaré- } \\
\text { Mato Grosso }\end{array}$ & Guamá & Maracanã & 673 & 193 & 2406 \\
\hline Flona Caxiuanã & Marajó & Gurupá & 118 & 86 & 556 \\
\hline $\begin{array}{l}\text { RDS Itatupã - } \\
\text { Baquiá }\end{array}$ & Marajó & Gurupá & 313 & 59 & 1496 \\
\hline Resex Mapuá & Marajó & Breves & 675 & 214 & 3566 \\
\hline $\begin{array}{l}\text { Resex Verde para } \\
\text { Sempre }\end{array}$ & Marajó & Gurupá & 2151 & 256 & 8964 \\
\hline $\begin{array}{ll}\text { Resex } & \text { Arioca } \\
\text { Pruanã } & \end{array}$ & Marajó & Bagre & 230 & 230 & 1212 \\
\hline $\begin{array}{l}\text { Resex de Gurupá- } \\
\text { Melgaço }\end{array}$ & Marajó & Breves & 617 & 87 & 3254 \\
\hline Resex Soure & Marajó & Soure & 1298 & 275 & 4882 \\
\hline $\begin{array}{l}\text { Resex } \quad \text { Terra } \\
\text { Grande Pracuúba }\end{array}$ & Marajó & Breves & 619 & 201 & 2839 \\
\hline $\begin{array}{l}\text { Resex Marinha de } \\
\text { Caeté-Taperaçu }\end{array}$ & Rio Caeté & Bragança & 352 & 351 & 1639 \\
\hline ResexAraí Peroba & Rio Caeté & $\begin{array}{l}\text { Augusto } \\
\text { Corrêa }\end{array}$ & 1244 & 270 & 4639 \\
\hline Resex Gurupi-Piriá & Rio Caeté & $\begin{array}{l}\text { Augusto } \\
\text { Corrêa }\end{array}$ & 459 & 459 & 2382 \\
\hline
\end{tabular}




\begin{tabular}{|l|l|l|l|l|l|}
\hline $\begin{array}{l}\text { Resex Marinha de } \\
\text { Tracuateua }\end{array}$ & Rio Caeté & Bragança & 2020 & 417 & 6544 \\
\hline Flona de Crepori & Tapajós & Itaituba & 51 & 51 & 119 \\
\hline Flona Tapajós & Tapajós & Aveiro & 716 & 166 & 2932 \\
\hline $\begin{array}{l}\text { ResexIpaú- } \\
\text { Anilzinho }\end{array}$ & Tocantins & Baião & 353 & 132 & 1367 \\
\hline Resex Rio Iriri & Xingu & Altamira & 100 & 100 & 388 \\
\hline Resex Rio Xingu & Xingu & Altamira & 74 & 74 & 268 \\
\hline $\begin{array}{l}\text { Resex Riozinho do } \\
\text { Anfrísio }\end{array}$ & Xingu & Altamira & 48 & 48 & 213 \\
\hline
\end{tabular}

Fonte: Dados da pesquisa, 2016.

Dos dados coletados por meio dos questionários foram utilizados aqueles referentes a 20.950 famílias residentes nas UCUS do estado do Pará. A partir destes dados foram realizadasanálises estatísticas descritivas com utilizaçãodo programa Pacote Estatístico para Ciências Sociais (SPSS).

As metodologias norteadoras para estimar a valoração dos recursos naturais das Unidades de Conservação como potencial econômico foram baseadas em Medeiros et al. (2011), a partir do qual quantificou-se a área, número de indivíduos, volume estimado da produção e estimativa do potencial econômico para avaliar a contribuição das Unidades de Conservação para a economia regional. Utilizaram-se também os argumentos de Motta (2011),que adotou modelos de valor econômico dos recursos ambientais voltados para Economia Verde.

Dessa forma, através das análises estatísticas dos dados coletados foram adotados como critérios para estimar a valoração dos processos produtivos: número total de informantes, volume produzido total (consumo e venda), preço médio de venda e a renda total proveniente da comercialização. Assim, quantificou-se o rendimento monetário das atividades pesqueiras, da produção da mandioca (Manihotesculenta Crantz) e do extrativismo de açaí (Euterpe oleracea) e castanha-do-Brasil (Bertholletia excelsa Bonpl )das 25 Unidades de Conservação de Uso Sustentável no estado do Pará, para avaliar o potencial das mesmas para o desenvolvimento de uma Economia Verde regional.

\section{Resultados e discussão} Perfil do grupo familiar das Unidades de Conservação

A população residente nas UCUS estudadas compreende 81.435 habitantes distribuídos em 52,8\% do gênero masculino e 47,2\% feminino, que compõem 20.386 
unidades domiciliares.Estes habitantes possuem significativa representatividade populacional nos municípios em que as UCUS estão inseridas. Destacam-se as Resex Verde para Sempre, Resex Mãe Grande de Curuçá, Resex Maracanã e Resex Marinha Soure, onde a população representa cerca de $30 \%, 28 \%, 21 \%$ e $20 \%$, respectivamente, do total da população dos municípios, considerando-se o Censo do IBGE de 2010.

A população economicamente ativa representa $62 \%$ dos habitantes das UCUS deste estudo, os jovens correspondem a 33,5\% e os indivíduos acima de 65 anos a 4,6\%. A razão de dependência é de $61,3 \%$ e a taxa de envelhecimento 4,6\%. Comparativamente aos dados da população estadual, observa-se uma congruência, já que 67,55\% da população têm entre 15 e 64 anos, entretanto a razão de dependência é menor com 48,04\% (IBGE, 2014). Destaca-se a razão de dependência mais elevada nas UCUS, o que acarreta em maior demanda do poder público por ações que privilegiem a área de educação, formação profissional, condições de trabalho e renda, atendendo assim, as necessidades das crianças e jovens, tendo em vista a continuidade desta população tão expressiva dentro destas Unidades de Conservação.

No que se refere à escolaridade, 63,43\% dos moradores possuem apenas ensino fundamental e $7,1 \%$ se declararam analfabetos. Similarmente a realidade encontrada no estado, onde 59,6\% das pessoas de 10 anos ou mais de idade não possuem instrução ou apenas o ensino fundamental incompleto. Quanto à ocupação principal, entre os representantes das unidades domiciliares, 25,24\% declararam-se como agricultores(as); $25,83 \%$ afirmaram ser pescadores(as), marisqueiros ou beneficiadores do pescado e; $6,9 \%$ extrativistas vegetais. Destaca-se que foram informadas além das citadas acima, outras 99 ocupações. É importante salientar que essas ocupações representam uma relação direta entre estas pessoas e o território já que $60 \%$ utilizam o espaço em que vivem como fonte de recurso e renda, seja através da agricultura familiar, atividades pesqueiras, extrativismo ou pela confecção de artesanato.

Os rendimentos familiares informados, em sua totalidade, foram obtidos pela produção e também por programas sociais de transferência de renda como Bolsa Família, Bolsa Verde, Bolsa Jovem, Previdência Rural, Programa Nacional de Geração de Emprego e Renda - Pronager, Benefício da Prestação Continuada (BPC) da Lei Orgânica da Assistência Social (LOAS) e aposentadoria. Sendo assim, 71,2\% dos entrevistados recebem até um salário mínimo ( $\mathrm{R} \$ 724,00$ em 2014), 19,88\% entre um e dois salários mínimos, enquanto apenas 4,45\% possuem renda familiar acima de dois salários 
mínimos. A renda média das famílias inseridas nessas UCUS é de $\mathrm{R} \$ 564,00$, o que é similar à realidade estadual, em que $68 \%$ da população recebem até um salário mínimo(IBGE, 2010).

\section{Sistema produtivo como mecanismo de desenvolvimento}

O cenário produtivo dessas 25 Unidades de Conservação de Uso Sustentável é composto, substancialmente, pelas atividades extrativistas vegetais, pesqueiras e agricultura. As atividades pesqueiras representam 53,51\% de todas as atividades realizadas pelos entrevistados; seguida pela produção vegetal com 30,58\% e 21,34\% para o extrativismo vegetal. Algumas dessas UCUS ainda realizam produção animal, madeireira e pecuária.

Considerando que cada Unidade de Conservação possui uma singularidade, e para analisar efetivamente as potencialidades da conjuntura produtiva como elementos da Economia Verde, foram efetuadas duas abordagens, primeiramente com os dados agrupados das 25 UCUS e, posteriormente, com os dados relativos aos volumes produzidos e renda de venda, sistematizados nos Quadros 02, 03 e 04 das unidades que apresentaram dados mais significativos para os produtos analisados.

\section{Extrativismo Vegetal}

Dentro do extrativismo vegetal realizados nas UCUS, a coleta do açaí possui maior expressividade com 48,58\% do total extraído, seguido pela castanha-do-Brasil com $24,02 \%$; tucumã $(6,5 \%)$; bacaba (6,4\%); e o restante distribuído entre a seringa, cupuaçu, andiroba e bacuri. Esses produtos são aproveitados pelos moradores para o consumo familiar, comercialização e confecção de artesanato. A castanha-do-Brasil e o açaí também foram os produtos extrativistas com maior impacto na economia das famílias analisadas,representando uma receita de $\mathrm{R} \$ 1.582 .514,19$ no ano de 2014 , auferida no conjunto de 775 extrativistas, equivalente a $\mathrm{R} \$ 2.041,95$ por família/ano.Esse sistema de extrativismo vegetal é realizado predominantemente com mão de obra familiar, em $85,49 \%$ das famílias entrevistadas, e os outros $14,51 \%$ contratam diaristas e mensalistas ou realizam mutirões. Os entrevistados relataram que as maiores dificuldades ou problemas para extração desses produtos extrativistas são: baixa representatividade das plantas por área e falta de assistência técnica. 
A comercialização do açaí e da castanha-do-Brasil é realizada predominantemente $(65,7 \%)$ pelos próprios extrativistas e o restante, $29,1 \%$ dependem de atravessadores e marreteiros e 5,2\% comercializam através de formas organizativas, tais como as associações e cooperativas. A falta de meios para escoar as mercadorias, a falta de transporte e o baixo preço oferecido pelo mercado foram as principais dificuldades apontadas na realização dessa atividade.

Destacam-se treze UCUS que tiveram maior representatividade de indivíduos extrativistas e também maiores volumes produzidos de castanha-do-Brasil e açaí. O açaí apresentou-se como o produto extrativista mais importante economicamente dentro das UCUS estudadas, principalmente naquelas inseridas na RI do Marajó, com destaque para as Resex’s Arioca Pruanã, Terra Grande Pracuúba, Mapuá, RDS ItatupãBaquiá e FlonaCaxiuanã.

Os extrativistas da Resex Arioca Pruanã produziram 233,23 toneladas de produtos extrativistas vegetais em 2015, sendo o açaí responsável por69\% desse volume.O maior percentual da produção $(70,5 \%)$ foi destinado a venda, gerando uma receita de $\mathrm{R} \$ 349.837,50$, equivalente a $\mathrm{R} \$ 6.247,00$ por família. Já na Resex Terra Grande e Pracuúba, o volume comercializado corresponde a $75 \%$ do total e a renda absoluta foi de R \$ 330.102,00, ou seja, R \$4.343,44 por família. A Resex Mapuá apresentou grande produção de açaí, com uma renda total de $\mathrm{R} \$ 239.561,34$, provenientes da comercialização por 77 extrativistas entrevistados, gerando uma renda de $\mathrm{R} \$ 3.111,18$ por família (Quadro 2).Os municípios de abrangência das UCUS localizadas na região do Marajó possuem pouca participação na atividade da extração vegetal do açaí considerando todo o Estado, já que contribuem com apenas 2,61\% do total(IDESP, 2011).

Na RDS Itatupã Baquiá, 46 entrevistados declaram ter produzido 82,8 toneladas de açaí, sendo que $70 \%$ da produção foi destinada para fins comerciais, que gerou uma rendatotal de $\mathrm{R} \$ 2.700,00$ por extrativista, no ano de 2014. Já na Flona Caxiuanã, a produção foi de $58 \mathrm{t}$, sendo $56 \%$ para comercialização, o que representou uma receita de $\mathrm{R} \$ 1.938,00$ por família naquele mesmo ano. O volume produzido e a receita gerada podem ser incrementados se sanados os problemas relatados pelos moradores, tais como os problemas climáticos, assistência técnica e poucas plantas por área. A Resex Soure, localizada no município de Soure possui um elevado potencial extrativista e obteve um volume de açaí muito significativo, mesmo considerando apenas 29 informantes, sendo que das 73 t coletadas, $80 \%$ foram para comercialização (Quadro 02). 
Quadro 02. Distribuição da produção extrativista da castanha-do-Brasil e açaí das Unidades de Conservação de Uso Sustentável, Pará, 2014.

\begin{tabular}{|l|l|l|l|}
\hline Unidade de Conservação & $\begin{array}{l}\text { Número } \\
\text { produtores }\end{array}$ & $\begin{array}{l}\text { Volume } \\
\text { estimado } \\
\text { (t) }\end{array}$ & $\begin{array}{l}\text { Renda total } \\
\text { R\$/ano })\end{array}$ \\
\hline ResexAriocaPruanã & 56 & 233,23 & $\mathrm{R} \$ 349.837,50$ \\
\hline Resex Terra Grande e Pracauúba & 76 & 220,07 & $\mathrm{R} \$ 330.102,00$ \\
\hline FlonaSaracaTaquera & 138 & 189,75 & $\mathrm{R} \$ 284.622,00$ \\
\hline ResexMapuá & 77 & 159,71 & $\mathrm{R} \$ 239.561,34$ \\
\hline RDS Itatupã Baquiá & 46 & 82,80 & $\mathrm{R} \$ 124.201,50$ \\
\hline Resex Soure & 29 & 73,39 & $\mathrm{R} \$ 110.088,00$ \\
\hline ResexChocoaré Mato Grosso & 89 & 65,12 & $\mathrm{R} \$ 97.680,60$ \\
\hline FlonaCaxiuanã & 45 & 58,16 & $\mathrm{R} \$ 87.236,25$ \\
\hline ResexTracuateua & 25 & 47,48 & $\mathrm{R} \$ 71.214,00$ \\
\hline Resex Gurupá Melgaço & 34 & 34,18 & $\mathrm{R} \$ 51.276,00$ \\
\hline Resex Tapajós Arapiuns & 19 & 21,42 & $\mathrm{R} \$ 32.134,50$ \\
\hline Resex Rio Xingu & 42 & 21,01 & $\mathrm{R} \$ 31.512,00$ \\
\hline Resex Verde para Sempre & 12 & 20,16 & $\mathrm{R} \$ 30.241,50$ \\
\hline Resex Riozinho do Anfrísio & 31 & 10,57 & $\mathrm{R} \$ 15.855,00$ \\
\hline Resex Rio Iriri & 56 & 9,13 & $\mathrm{R} \$ 13.690,50$ \\
\hline Total & 775 & $1.246,18$ & $\mathrm{R} \$ 1.582 .514,19$ \\
\hline
\end{tabular}

Fonte: Dados da pesquisa, 2016.

Em relação à castanha-do-Brasil, as UCUS que evidenciaram maiores potencialidades foram a Flona Saracá Taquera, situadas em Oriximiná e as Resex's Rio Iriri, Rio Xingu e Riozinho do Anfrísio, pertencentes ao município de Altamira. A produção extrativista da Flona Saracá Taquera apresentou uma renda de comercialização expressiva, com valor de venda em $\mathrm{R} \$ 284.622,00$, ou seja, $\mathrm{R}$ \$ 2.062,00 família/ano, tendo uma participação importante na vida dos moradores, no que se refere à complementação da renda monetária. Em relação ao consumo familiar, 25,6\% do volume total foi produzido para este fim. Essa UC está localizada no município de Oriximiná, que possui grande potencial extrativista da castanha-do-Brasil, tendo, em 2011, produzido1680 toneladas (FAPESPA, 2016). 
Dentre o grupo de Resex's localizadasna região do Xingu, destaca-se a Resex Rio Xingu, com coleta de $21 \mathrm{t}$ de castanha-do-Brasil no ano de 2014, gerando uma renda de R\$ 31.512,00, ou seja, R\$ 750,00 por família. As outras UCUS (Resex Riozinho do Anfrísio e Resex Rio Iriri) geraram uma renda total de $\mathrm{R} \$ 29.545,50$, com um volume coletado de 19,7 t, correspondente a $\mathrm{R} \$ 364,00$ por extrativista. O extrativismo do açaí e da castanha-do-Brasil na região do Xingu não apresenta relevância econômica no contexto estadual, entretanto, o município de Altamira produziu 250 t de castanha-doBrasil no ano de 2014(FAPESPA, 2016). Assim, considerando apenas a amostragem de 103 entrevistados, as UCUS nessa RI contribuíram em 14,8\% do total da produção estadual desse produto. Ademais, ressalta-se que, se for avaliado o total de famílias extrativistas, a contribuição dessas UCUS no cenário municipal pode ser substancialmente superior.

De forma geral, as atividades extrativistas dessas UCUS poderiam ser potencializadas com ações de assistência técnica visando à melhoria do manejo, coleta, transporte e armazenamento e dos canais de comercialização. Foram relatadas pelos entrevistados muitas dificuldades que impedem maiores avanços da produtividade, tais como: problemas de sazonalidade entre épocas chuvosas e secas; baixo preço de venda; poucas plantas por área; falta de assistência técnica; distância do local de extração e dificuldades relativas à coleta dos frutos, como o transporte.

\section{Atividade pesqueira}

Entre os peixes mais pescados destacam-se o Bagre (LuciopimelodusPlatanus), Tucunaré (Cichlaocellaris), Pescada (Cynoscionsp.), Pacu (Piaractusmesopotamicus) e Tainha (Mugil brasiliensis), representando62\% do volume total.A atividade pesqueira gerou uma renda de $\mathrm{R} \$ 6.389 .422,88$, decorrente da comercialização,em um volume total de 1331 toneladas de diferentes espécies (Quadro 3).A comercialização do pescado é, em $74,65 \%$ dos casos, realizada por marreteiros/atravessadores ou compradores nos locais. A mão de obra utilizada nesta atividade é exclusivamente familiar, com predomínio de embarcações pequenas, de até 8 metros, e também a utilização de instrumentos simples, como redes, anzóis e tarrafas e outros característicos da pesca artesanal.

Destacam-se entre as UCUS que tiveram um elevado volume pescado as Resex's marinhas de Tracuateua, Gurupi Piriá, Caeté Taperaçu e Soure. Na Resex Tracuateua 
foram 798 entrevistados que declararam ter pescado um volume de $736 \mathrm{t}$, gerando uma renda total de $\mathrm{R} \$ 3.543 .236,35$, equivalente a $\mathrm{R} \$ 4.440,14$ por família, no ano de 2014. Na Resex Gurupi Piriá, neste mesmo ano, o volume de pescado foi de 123,92 t referentes a 460 entrevistados, com valor de renda de venda de $\mathrm{R} \$ 619.602,50$. No que se refere à região do Marajó, o volume de pesca mais expressivo foi encontrado na Resex Marinha de Soure, com 70,7 t de pescados por 288 pescadores, o que gerou uma renda de $\mathrm{R} \$ 353.420,00$, ou seja, $\mathrm{R} \$ 1.227,00$ por pescador. O volume consumido representou $24,10 \%$ do total, demonstrando que a maior parte da produção é voltada para comercialização e, consequentemente, fonte de renda destas famílias (Quadro 03).

Nas UCUS inseridas as margens dos rios amazônicos, destacam-se as Resex's Verde para Sempre, Renascer, Rio Iriri, Rio Xingu e Riozinho do Anfrísio, que juntas obtiveram um volume de 176 toneladas de pescados distribuídos entre 691 pescadores. Salienta-se que nessas UCUS a atividade pesqueira possui caráter secundário, onde as práticas extrativistas e agrícolas são predominantes. Ademais, diante do potencial e abundância de rios e igarapés nessas áreas, estes valores poderiam ser superiores se tivessem investimentos e ações públicas voltadas para a gestão e manejo pesqueiro que tanto beneficiaria estas famílias ribeirinhas.

Quadro 03. Distribuição da atividade pesqueira nas Unidades de Conservação de Uso Sustentável, Pará, 2014.

\begin{tabular}{|l|l|l|l|}
\hline Unidades de Conservação & Número de produtores & $\begin{array}{l}\text { Volume } \\
\text { pescado (t) }\end{array}$ & $\begin{array}{l}\text { Renda } \\
\text { total(R } \$ \text { /ano) }\end{array}$ \\
\hline ResexTracuateua & 798 & 736,99 & $\mathrm{R} \$ 3.543 .236,35$ \\
\hline Resex Gurupi Piriá & 460 & 123,92 & $\mathrm{R} \$ 619.602,50$ \\
\hline Resex Caeté Taperaçu & 335 & 77,79 & $\mathrm{R} \$ 388.945,75$ \\
\hline Resex Soure & 288 & 70,68 & $\mathrm{R} \$ 353.420,00$ \\
\hline Resex Renascer & 83 & 50,34 & $\mathrm{R} \$ 151.020,00$ \\
\hline Resex Rio Xingu & 162 & 46,61 & $\mathrm{R} \$ 186.420,00$ \\
\hline ResexChocoaré Mato Grosso & 233 & 42,40 & $\mathrm{R} \$ 296.821,00$ \\
\hline Resex Maracanã & 171 & 41,73 & $\mathrm{R} \$ 166.900,00$ \\
\hline Resex Rio Iriri & 247 & 39,20 & $\mathrm{R} \$ 156.780,00$ \\
\hline Resex Verde para Sempre & 124 & 21,19 & $\mathrm{R} \$ 109.744,29$ \\
\hline Resex Riozinho do Anfrísio & 75 & 19,51 & $\mathrm{R} \$ 78.028,00$ \\
\hline Resex Mãe Grande de Curuçá & 93 & 17,55 & $\mathrm{R} \$ 105.324,00$ \\
\hline ResexAraí Peroba & 106 & 16,11 & $\mathrm{R} \$ 96.666,00$ \\
\hline FlonaCaxiuanã & 57 & 13,34 & $\mathrm{R} \$ 66.720,00$ \\
\hline
\end{tabular}




\begin{tabular}{|l|l|l|l|}
\hline FlonaSaracaTaquera & 174 & 7,95 & $\mathrm{R} \$ 39.770,00$ \\
\hline ResexIpaúAnilzinho & 206 & 6,01 & $\mathrm{R} \$ 30.025,00$ \\
\hline Total & 3612 & 1331,32 & $\mathrm{R} \$ 6.389 .422,88$ \\
\hline
\end{tabular}

Fonte: Dados da pesquisa, 2016.

\section{Produção agrícola}

Em relação à produção agrícola, os principais produtos foram a mandioca/macaxeira $(69,3 \%)$, milho $(9,9 \%)$, feijão $(3,3 \%)$; banana $(3,2 \%)$ e o restante distribuído entre abacaxi, arroz, melancia e hortaliças.A produção agrícola é uma atividade significativa na maioria das UCUS estudadas e é caracterizada como uma agricultura de subsistência, onde a mão de obra é predominantemente familiar. Todo o núcleo familiar está envolvido com o plantio, colheita e eventual beneficiamento, com utilização mínima de insumos externos sendo, portanto de baixo impacto ambiental.

A mandioca é o principal produto agrícola beneficiado pelas famílias, destinada à produção de farinha, o alimento fundamental da dieta dos moradores e de boa parte da população estadual. Em termos quantitativos, foram produzidas 1.013,37 toneladas, que geraram uma renda total de venda de $\mathrm{R} \$ 1.216 .051,87$ distribuídos para 1.071famílias. Quando questionados sobre os problemas na produção de mandioca, 62,2\% dos entrevistados afirmaram que têm muito trabalho para pouca produção e 17,8\% relataram a distância do mercado consumidor. Os outros problemas relatados foram relativos à qualidade do solo, falta de mão-de-obra e ocorrência de doenças e pragas na lavoura.

Em termos da produtividade da mandioca, as UCUS inseridas na RI do rio Caeté apresentaram os mais expressivos volumes de produção. Os agricultores das Resex’s Tracuateua e Gurupi Piriá obtiveram um volume total de produção superior a 130 toneladas, o que gerou uma renda de $\mathrm{R} \$ 1.100,00$ por família/ano, advinda da venda da farinha de mandioca. De forma menos significativa, comparativamente as outras UCUS desta RI, a Resex Caeté Taperaçu gerou uma renda monetária de R \$107.032,80, com a produção de 89 t de farinha de mandioca. Destaca-se o fato destas UCUS serem marinhas com potencial superior para práticas pesqueiras. Nesse caso, a renda gerada pela comercialização da farinha de mandioca agrega consideravelmente a receita doméstica dessas famílias (Quadro 04). 
Quadro 04. Distribuição da produção da mandioca das Unidades de Conservação de Uso Sustentável Pará, 2014

\begin{tabular}{|l|l|l|l|}
\hline Unidade de Conservação & $\begin{array}{l}\text { Número de } \\
\text { produtores }\end{array}$ & $\begin{array}{l}\text { Volume } \\
\text { estimado (t) }\end{array}$ & Renda total(R\$/ano) \\
\hline Resex Gurupi Piriá & 130 & 176,05 & $\mathrm{R} \$ 211.260,00$ \\
\hline Resex Tracuateua & 145 & 132,42 & $\mathrm{R} \$ 158.904,72$ \\
\hline Resex Arioca Pruanã & 119 & 110,27 & $\mathrm{R} \$ 132.322,80$ \\
\hline Resex Chocoaré Mato Grosso & 102 & 98,12 & $\mathrm{R} \$ 117.744,24$ \\
\hline Flona Saracá-Taquera & 156 & 97,00 & $\mathrm{R} \$ 116.397,60$ \\
\hline Resex Caeté Taperaçu & 50 & 89,19 & $\mathrm{R} \$ 107.032,80$ \\
\hline Resex Mapuá & 96 & 86,08 & $\mathrm{R} \$ 103.298,11$ \\
\hline Flona Caxiuanã & 66 & 59,17 & $\mathrm{R} \$ 71.002,80$ \\
\hline Resex Rio Iriri & 58 & 58,25 & $\mathrm{R} \$ 69.900,00$ \\
\hline $\begin{array}{l}\text { Resex Terra } \\
\text { Pracauúba }\end{array}$ & 60 & 48,53 & $\mathrm{R} \$ 58.239,60$ \\
\hline Resex Renascer & 38 & 33,19 & $\mathrm{R} \$ 39.830,40$ \\
\hline Resex Riozinho do Anfrísio & 26 & 14,91 & $\mathrm{R} \$ 17.893,20$ \\
\hline Resex IpaúAnilzinho & 28 & 10,19 & $\mathrm{R} \$ 12.225,60$ \\
\hline Total & 1074 & 1013,37 & $\mathrm{R} \$ 1.216 .051,87$ \\
\hline
\end{tabular}

Fonte: Dados da pesquisa, 2016.

Na RI do Marajó destacam-se na produção de mandioca asResexAriócaPruanã, Flona Mapuá, Flona Caxiuanã e Resex Terra Grande e Pracuúba. Assim, foi informado um volume produzido de 110 toneladas, correspondendo a uma receita de $\mathrm{R} \$ 1.109,00$ no ano de 2014, para cada um dos 119 entrevistados da Resex Arioca Pruanã. A Resex Mapuá produziu cerca de 86 toneladas, divididos para 96 produtores, o que gerou uma renda monetária corresponde a $\mathrm{R} \$ 1.076,00$ por ano por produtor. Já a Resex Terra Grande e Pracauúba, teve uma produção de 48 t de farinha de mandioca, que gerou uma receita de $\mathrm{R} \$ 58.239,60$, dividida para 60 pessoas no ano de 2014. Essas UCUS não seguem o potencial agrícola dos municípios de Breves e Bagre devido aos problemas de muito trabalho para pouca produção e distância do mercado consumidor, conforme relatado pelos entrevistados. Entretanto, a venda da farinha de mandioca é muito importante na região porque agrega renda monetária para essas famílias que também realizam uma significativa comercialização de peixes e de extrativismo vegetal.

As Reservas Extrativistas Rio Iriri e Riozinho do Anfrísio, localizadas na RI do rio Xingu, obtiveram juntas um volume de produção da farinha de mandioca de 73 toneladas, o que gerou, em média, uma receita monetária de $\mathrm{R} \$ 1.200,00$ e $\mathrm{R} \$ 688,00$, 
respectivamente. Já na RI do baixo Amazonas destacam-se as UCUS Renascer e Flona Saracá-Taquera, apresentando a segunda, produção muito relevante em nível das outras UCUS estudadas, com $97 \mathrm{t}$ de mandioca produzida, que gerou uma renda de venda de $\mathrm{R} \$ 746,00$ por entrevistado no ano de 2014.

A produção agrícola é muito importante na vida destas famílias, tanto na complementação da renda monetária, quanto no que se refere as relações sociais, já que as famílias realizam parcerias para o beneficiamento e produção de farinha de mandioca. Essa atividade também é uma garantia de segurança alimentar para as famílias, que destinam entre $30 \%$ e $60 \%$ da produção de mandioca para o consumo familiar.

$\mathrm{Na}$ proposição dos sistemas produtivos como elementos norteadores do desenvolvimento da Economia Verde, de forma integrada, as 25 Unidades de Conservação de Uso Sustentável analisadas neste estudo produziram um volume de 3.871 toneladas divididos entre 6.053 indivíduos, representando uma receita de $\mathrm{R} \$$ 9.800.218,00 no ano de 2014, provenientes das atividades pesqueiras, produção de mandioca e extrativismo do açaí e da castanha-do-Brasil. A atividade pesqueira teve o maior volume produzido, cerca de 1.350 toneladas e também uma receita monetária superior, tanto no que se refere à renda advinda da comercialização com $\mathrm{R} \$ 6.390 .605,00$, quanto de autoconsumo que foi de $\mathrm{R} \$ 1.433 .945,34$.

De forma geral, a renda anual distribuída pelo número de informantes produtores ou pescadores é bem significativa - cerca de $R \$ 5.000,00$, sendo equivalente a $R \$ 2.217,00$ procedentes da venda da castanha-do-Brasil e açaí; $\mathrm{R} \$ 1.643,25$ derivada das atividades pesqueiras e $\mathrm{R} \$ 1.127,91$ da venda da farinha de mandioca. Nesse sentido, os moradores dessas UCUS normalmente realizam mais de uma atividade produtiva, que somadas agregam ainda mais renda monetária a essas famílias. Além disso, a renda da comercialização produtiva é complementar às outras fontes de transferência de renda, via programas sociais. Outro ponto de extrema importância é a garantia de segurança alimentar já que os peixes, a mandioca e seus derivados e os frutos, que representam $95 \%$, $90 \%$ e $43 \%$, respectivamente, são os alimentos mais consumido pelos moradores.

Admite-se que os dados demonstrados através da pesquisa corroboram com a concepção de Medeiros et al. (2011), em que a contribuição das Unidades de Conservação brasileiras para a economia nacional se dá principalmente pela valorização de bens e serviços associados à exploração de produtos florestais, em especial os não madeireiros. Ao se pensar na realidade desses espaços, as comunidades realizam a associação da 
produção agrícola de baixo impacto ambiental com as práticas extrativistas (vegetal ou pesqueira), configurando um cenário singular destes territórios frente a outros modelos de Unidade de Conservação.

Outro ponto importante a considerar é o baixo o número de pessoas inseridas nessas UCUS, média de menos de um habitante por hectare. Essas famílias dependem diretamente dos recursos naturais existentes nessas áreas e, assim, contribuem para a preservação da vegetação e conservação dos recursos hídricos, garantindo indiretamente a reserva de carbono nessas áreas que também é um elemento preconizado na Economia Verde.

Assim, para compreensão desses elementos norteadores, remete a análise da realidade social e produtiva das famílias inseridas nas UCUS,os paradigmas para uma efetiva sustentabilidade baseando no estudo da Unep (2015), onde a Economia Verde configura-se no aprimoramento do bem estar humano e social através da inclusão social e utilização eficiente dos recursos naturais. E dentre as iniciativas na esfera social estão: erradicação da pobreza; segurança alimentar e nutricional; equidade; acesso ao trabalho, saúde, educação e cultura; desenvolvimento rural e urbano. Dentre as medidas compensatórias propostas por esse modelo de desenvolvimento, estão as tecnologias mais limpas, ecoeficiência no consumo de recursos naturais, energias renováveis, gestão sustentável de resíduos, apoio as cadeias produtivas e formas de beneficiamento dos produtos extrativistas.

Este modelo representa o princípio norteador de uma nova forma de relação do homem com o meio ambiente e, assim, torna-se presente nas reflexões contemporâneas sobre a dimensão ambiental do processo econômico diante das transformações decorrentes do atendimento às demandas antrópicas (DINIZ e BERMANN, 2012).

Nesses termos, há de se considerar a concepção de sustentabilidade e a real transformação social e ambiental nesses territórios, podendo causar impactos de diferentes magnitudes na vida destas populações tradicionais. Entretanto, a geração de renda, os meios de ocupação, a segurança alimentar auferidas pelos sistemas produtivos garantem a continuidade e melhores condições de vida dessas famílias. Essa concepção associada a preservação ambiental, preceitua um modelo sustentável da Economia Verde para essas famílias tradicionais comparadas às famílias residentes em outros espaços rurais. 
Essas alterações ambientais e sociais vêm provocando modificações no arcabouço econômico, para promover formas mais eficientes e sustentáveis das tomadas de decisões e assim tornar o crescimento mais expressivo. A respeito desta questão, há de assinalar que a Economia Verde possui seus preceitos contrários às vertentes metodológicas das economias ambientais e ecológicas, que consideram o meio ambiente como um fator impeditivo na busca de um crescimento ilimitado. E transferem, assim, um valor intrínseco aos bens naturais, excluindo as relações sociais como mediadoras da interligação dos sistemas econômicos com os ecossistemas (SOUZA-LIMA, 2004). Ademais, a Economia Verde fundamenta-se nos seguintes preceitos: alcançar a sustentabilidade ecológica e a equidade social.

O modelo defendido pela Economia Verde tem papel catalisador do crescimento para erradicação da pobreza e pensar na inércia econômica dessas famílias é associar um modelo restritivo e excludente. Salienta-se que uma vez realizados investimentos e ações promissoras que visam o crescimento econômico como instrumento calcado na inclusão social, esses territórios se configurariam em formas de tecnologias limpas, com uso racional dos recursos ambientais, e representando para estas famílias um importante elemento de equidade e prosperidade.

Diegues (1996) defende que as Reservas Extrativistas, principal tipo de UCUS, visam assegurar o direito histórico das populações tradicionais (seringueiros, ribeirinhos e pescadores) ao território e derivam de um modelo de uso da floresta com baixo impacto sobre o ecossistema. Segundo este autor, as Resex podem ser uma alternativa interessante para o desenvolvimento da Amazônia, por combinar o uso produtivo dos recursos florestais com a sua conservação. Nessa perspectiva, Machado et al.(2008) argumentam que estas áreas indicam um paradigma de desenvolvimento social, pois associam a conservação ambiental com serviços sociais como a segurança alimentar, composição de renda e preservação da diversidade cultural.

Por outro lado, esta alternativa de organização territorial, socioeconômica e ambiental é questionada devido às controvérsias a respeito de suas contribuições para o desenvolvimento sustentável. Segundo seus críticos, os processos de criação destes espaços protegidos vêm acompanhados de conflitos e impactos de ordem política, legal e socioeconômica,decorrentes da desterritorialização dos grupos sociais, sejam tradicionais ou não (VALLEJO, 2009). Nessa perspectiva, o extrativismo vegetal, elemento base das Reservas Extrativistas, é criticado por Homma (2012) que considera insustentável a 
viabilidade produtiva e econômica do extrativismo tradicional. Assim, segundo este autor, o extrativismo não seria uma alternativa de desenvolvimento sustentável na Amazônia, devido a sua instabilidade temporal e espacial, tendendo ao desaparecimento no médio e longo prazo em virtude dos baixos rendimentos da terra e da mão-de-obra, aliados ao baixo progresso tecnológico e à substituição por outros produtos, ou mesmo a domesticação dos produtos da floresta.

Contrariando a perspectiva de Homma (2012) sobre a inviabilidade econômica do extrativismo, Anderson (1994) argumenta que essas críticas não levam em consideração o grande potencial de rendimento econômico de produtos florestais não madeireiros e, sobretudo, o baixo desempenho econômico e os custos sociais e ambientais de outros usos não sustentáveis da terra no ambiente amazônico. Além disso, Anderson (1994), e outros autores como Almeida (1994), consideram que as Reservas Extrativistas é um modelo de desenvolvimento sustentável voltado para a realidade amazônica. E para sua efetiva consolidação são necessárias ações voltadas para a diversificação da produção, modernização do processo de produção, processamento e comercialização, como também para a melhoria de vida da população local. No sentido mais amplo, à medida que se eleva a produtividade extrativista e aumenta à rentabilidade destas práticas, consequentemente diminuiria pressão para intensificação de outras atividades produtivas causadoras de desmatamento.

Seguindo esta mesma linha, D’Antona (2003) defende que as Resex representam um marco no processo de ocupação do espaco amazônico, com propostas pretéritas e vigentes de desenvolvimento, uso e ocupação das terras. Além disso, representam uma alternativa de desenvolvimento com respeito à diversidade cultural e ambiental, o que pode ser encaixado nos modelos defendidos pela Economia Verde.

As Unidades de Conservação de Uso Sustentável estudadas podem ser pensadas nos pressupostos da Economia Verde, já que a mesma se sustenta em um conjunto de processos produtivos de uso sustentável que pode contribuir para a sustentabilidade socioambiental desses locais. A apropriação racional dos recursos naturais é uma importante fonte de renda monetária para essas famílias, além de garantir a manutenção dos núcleos familiares e também a preservação dos ecossistemas.

Além do viés econômico, o extrativismo vegetal ou as atividades pesqueiras garantem o acesso ao território por que são práticas legalizadas de uso sustentável destes espaços protegidos. Assim, essas pessoas precisam criar mecanismos de reprodução 
social nesses espaços, tendo nos mesmos sua fonte de alimento, água, moradia e renda, o que configura uma relação de dependência com o território. Sobretudo, os benefícios da Economia Verde podem ser mais efetivos na esfera microeconômica, podendo reduzir a pobreza e ao mesmo tempo investir no capital natural com a premissa da preservação e desenvolvimento.

Para uma efetiva estruturação sustentável, práticas de gestão precisam ser implementadas visando à regularização fundiária, a assistência técnica e alternativas produtivas ao extrativismo e organização social das famílias envolvidas. O desafio para a consolidação e o desenvolvimento das Unidades de Conservação de Uso Sustentável é conseguir uma gestão eficiente, principalmente por parte dos órgãos públicos, a fim de alcançar o desenvolvimento regional e a manutenção desses ecossistemas.

As estratégias de desenvolvimento regional precisam ser pensadas de forma que os atores sociais sejam os elementos fundamentais e que a primazia seja a equidade social voltada para as especificidades socioculturais dessas áreas tão singulares, de forma a garantir a sustentabilidade e a autonomia dessas populações tradicionais.

\section{Considerações finais}

No conjunto de proposições, as Unidades de Conservação de Uso Sustentável estudadas podem configurar em uma alternativa emergente para uma solidificação da Economia Verde como proposta de desenvolvimento e sustentabilidade desses territórios, já que possuem como elemento basilar a preservação ambiental, focalizada para garantir o acesso a recursos e proporcionar melhoria das condições de vida das populações extrativistas. Nesse ponto, os dados desta pesquisa indicam que a partir de um sistema produtivo integrado, as famílias, inseridas nas UCUS estudadas, conseguem utilizar racionalmente os recursos naturais, agregando uma estrutura produtiva exitosa no sentido de gerar uma renda monetária acima dos padrões de uma agricultura de subsistência convencional, tornando-se disponível para atender as demandas das unidades familiares. Dessa maneira, os dados produtivos apresentados evidenciam os parâmetros norteadores da Economia Verde no que se refere à geração de renda monetária, a condição de sobrevivência utilizando os recursos naturais e a garantia de segurança alimentar destas famílias, proporcionando, ainda, acesso ao território e a continuidade e perenidade dos recursos ambientais. 
A sustentabilidade e a viabilidade das Unidades de Conservação de Uso Sustentável, como mecanismos de desenvolvimento da Economia Verde, dependem de uma efetiva estruturação dos sistemas produtivos, criando meios de aumentar a competitividade dos produtos da floresta frente aos demais produtos do mercado e, dessa forma, a partir da ideia de sustentabilidade, oferecer um suporte substancial para melhoria das condições econômicas e sociais destas populações extrativistas, contribuindo, assim, para um sólido desenvolvimento regional

\section{Referências bibliográficas}

ANDERSON, A. et al (org). O destino da Floresta: reservas extrativistas e desenvolvimento sustentável na Amazônia. Rio de Janeiro: Relume/Dumará - Curitiba, PR: Instituto de Estudos Amazônicos, 1994.

BRASIL. Lei $n$. 9.985, de 18 de julho de 2000. Institui o Sistema Nacional de Unidades de Conservação da Natureza - SNUC. Brasília, 2000.

CADASTRO NACIONAL DE UNIDADES DE CONSERVAÇÃO (CNUC). Dados consolidados. Disponível em <http://www.mma.gov.br/areas-protegidas/cadastro-nacional-deucs/dados-consolidados>. Acesso em fevereiro de 2017.

D'ANTONA, A. de O. Garantir a terra, garantia da Terra? Reservas Extrativistas na Amazônia Legal Brasileira. Tese de Doutorado - Universidade de Campinas, 2003, 188 p.

DIEGUES, A. C. O mito moderno da natureza intocada. São Paulo: HUCITEC, 1996.

DINIZ, E.M.; BERMANN, C.Economia verde e sustentabilidade. Estudos avançados, 26,74, 323-329, 2012.

Fundação Amazônia de Amparo a Estudos e Pesquisa - FAPESPA. Anuário estático do estado do Pará. Disponível em<www.fapespa.pa.gov.br/>. Acesso em fevereiro de 2016.

IBGE (Brasil). Disponível em <http://www.cidades.ibge.gov.br/>. Acesso em fevereiro de 2016.

INSTITUTO DE DESENVOLVIMENTO ECONÔMICO, SOCIAL E AMBIENTAL DO PARÁ - IDESP. Cadeias de comercialização de produtos florestais não madeireiros na Região de Integração Baixo Amazonas, Estado do Pará: relatório técnico 2011. Belém: IDESP, 2011.

HOMMA, A.K.O. Extrativismo vegetal ou plantio: qual a opção para a Amazônia? Estudos avançados, 26 (74), 2012.

JACOBI, P.R.; SINISGALLI, P.A.A. Governança ambiental e economia verde. Ciência\& Saúde Coletiva, 17(6),1469-1478, 2012.

LEFF, E. Educação ambiental e desenvolvimento sustentável. In: REIGOTA, M. (org.) Verde cotidiano: o meio ambiente em discussão. Rio de Janeiro: DP\&A, 1999. 148p. 
MACHADO, J.G.R.; PAMPLONA, J.B. A ONU e o desenvolvimento econômico: uma interpretação das bases teóricas da atuação do PNUD. Economia e Sociedade, Campinas, v. 17, n. 1 (32), p. 53-84, abr. 2008.

MEDEIROS, R.; YOUNG; C.E.F. Contribuição das unidades de conservação brasileiras para a economia nacional: Relatório Final. Brasília: UNEP-WCMC, 2011, 120p.

MISOCZKY, M.C; BÖHM, S. From sustainable development to green economy: the constant and accelerated onslaught of capital on nature. Caderno EBAPE.BR, v. 10, $\mathrm{n}^{\circ} 3$, artigo 5, Rio de Janeiro, Set. 2012.

MOTTA, R.S. Valoração e precificação dos recursos ambientais para uma economia verde. Revista Política Ambiental, v.8, 93-103, 2011.

MOORE, J. W. Ecology, capital and the natures of our times: a theory of crisis in the capitalist world-ecology. Journal of World-System Analysis, v. 17, n. 1, p. 108-147, 2011.

OLIVEIRA. J.A.P. "Rio+20: What we can learn from the process and what is missing". Cad. EBAPE.BR, v. 10, n 3, Rio de Janeiro, 2012.

Programa das Nações Unidas para o Meio Ambiente -PNUMA, 2011, Caminhos para o Desenvolvimento Sustentável e a Erradicação da Pobreza - Síntese para Tomadores de Decisão, www.unep.org/greeneconomy. Acesso em fevereiro de 2016.

SOUZA-LIMA, J.E. Economia ambiental, ecológica e marxista versus recursos naturais.Revista FAE. Curitiba, v.7, n.1, p.119-127, 2004.

UNITED NATIONS ENVIRONMENTAL PROGRAMME - UNEP.Green economy report: a preview 2010. Disponível em: <http://www.unep.org/pdf/GreenEconomyReport>. Acesso em 05 de outubro de 2014.

VICTOR, P. A. Ecological economics and economic growth. Annals of the New York Academy of Sciences. n.1185, p.237-45, 2010.

YOUNG, C. E. F. Potencial de crescimento da Economia Verde no Brasil. Política Ambiental: Economia Verde: Desafios e Oportunidades, n.8, p.90-9, 2011.

World Conservation Union (IUCN); WideFund for Nature (WWF).Management effectiveness in Forest protected areas. A Proposal for a Global System ofAssessment.Geneva, Switzerland, 1999. 